Grammatik als Appositionssatz an ein unmittelbar vorangegangenes Nomen anlehnen". Freilich sagen wir nun nicht: „Handelt v. is aber von Juda, so muß mithin dieses Nomen auch Juda gewesen sein", sondern umgekehrt: $\mathrm{Da}$ in v. soab von Juda die Rede ist und il (d) auf Juda zurückweist, so mul auch in v. II f. von Juda die Rede sein.

Ich wüßte weiter keine Schwierigkeiten, die sich uns noch entgegenstellen könnten, und bin damit am Ende meiner Ausfuhrungen. Sollten sie das Verständnis von Gen 49 ro gefördert haben, ich wurde mich freuen.

[Abgeschlossen am 20. April 1909.]

\title{
Nachwort des Herausgebers.
}

Es versteht sich von selbst; daß die Autoren allein für den Inhalt ihrer Artikel und die in denselben ausgesprochenen Urteile verantwortlich sind. Der Herausgeber enthält sich daher in der Regel jeder Bemerkung, auch wenn er mit der Ansicht nicht ubereinstimmt, welche die veröffentlichte Arbeit vertritt. Wenn diesmal eine Ausnahme gemacht wird, so geschieht dies ebenfalls nicht, um in eine Diskussion oder Kritik der vorgetragenen Erklärung einzutreten, sondern nur, um auf die Moglichkeit einer in der Arbeit nicht berücksichtigten Auffassung hinzuweisen.

Es ist erwahnt, daß die verschiedensten Exegeten v. 10 ganz oder doch teilweise als Interpolation ansehen (SCHRÖDER' selber beschränkt diese auf den dritten Stichos des Verses), und daß fur של das die Schwierigkeit der Stelle verursacht, die Lesung מינְלה vorgeschlagen sei (vgl. hierfür bes. GIESEBRECHT Beiträge zur Jesaiakritik 1890, S. 29, und C. J. BALL The Book of Genesis 1896 S. 109f). Dab starke Grunde für die von Wellhausen und STADE vertretene Annahme der Interpolation des ganzen Verses im Wortlaut und Zusammenhang vorliegen, kann nicht in Abrede gestellt werden; daß dabei eine besondere Tendenz mitspiele und erst den Ausschlag gebe, wird mit Unrecht vermutet. Lábt man sich aber von den im Texte vorhandenen Gründen leiten und hält die Konjektur von משלה für wahrscheinlich, so hat man nicht immer noch der Meinung nachzuhängen, als ob der interpolierte Vers einen messianischen Sinn haber musse. Man begeht damit einen Fehler, der auch 
in àhnlicher Weise anderswo zu Milgriffen geführt hat. Wie man bei der Exegese nicht uberall, wo die Tradition es will, eine messianische Deutung $z u$ suchen hat, so dürfen nicht alle Funde bei den Ausgrabungen religiós gedeutet werden. Denn nicht alle Gegenstände, die man findet, sind religiöse Gegenstande, nicht jede aufgedeckte Säule ist eine Mașșebe, der von SELLIN in Ta'annek gefundene "Räucheraltar" ist kein kultischer Gegenstand, sondern ein Kohlenbecken eines vornehmen Hauses in der Art des Jer $3622 \mathrm{ff}$. beschriebenen, und die religiöse Deutung des Satzes: „Über meinem Haupte ist jemand, der da ist uber die Städte", den HROZNY auf einem von SELLIN in Taannek gefundenen Tontäfelchen gelesen hat, und die Verwendung desselben als Argument für altsemitischen Monotheismus sind auf alle Falle verfruht und übereilt gewesen, liest doch jetzt Ungnad (s. Gressmann, Aitorientalische Texte und Bilder zum Alten Testamente, Bd. I, 1909, S. I29) vielmehr: „Auf meinem Haupte ist jeder, der den Städten.... u und erklärt den Sinn für ganz unklar.

Lassen wir also die Interpolation Gen 49 ro sagen, was sie sagt:

„Nicht wird das Zepter von Juda weichen, noch der Herrscherstab von zwischen seinen Füßen, bis daß kommen wird sein Beherrscher

und ihm der Gehorsam der Völker gehört,"

und läßt man sich ferner nicht durch den Gedanken an eine messianische Aussage irreleiten, so bietet sich als das natürlichste Verständnis dieser Worte, da $\$$ in ihnen der geschichtliche Endpunkt der judaischen Herrschaft angegeben und auf den Herrscher hingewiesen wird, der Juda das Zepter aus der Hand nimmt. Dieser Herrscher aber ist niemand anders als Nebukadnezzar und nur diesen hat der Interpolator im Auge. Der Erzvater Jakob sollte gerade so gut das Ende des judäischen Reiches kennen, wie nach der Interpolation Hos I 7 der Prophet Hosea die Rettung Jerusalems im Jahre 7or vor Sanherib. $\mathrm{Da}$ aber die Anschauung von Nebukadnezzar als dem zum Herrscher Judas bestimmten König nichts Auffallendes haben kann, beweist Jer 27 , wo ausdrücklich erklärt ist, daß Jahwe ihm die Herrschaft uber Juda und, was wohl $\mathrm{zu}$ beachten, auch uber die Völker gegeben hat, vgl. Jer $274 \mathrm{ff}$. Wie Jer 27 erscheint dem Interpolator Nebukadnezzar als der Knecht Jahwes (vgl. noch Jer 259 43 10), dem der Gehorsam der Völker, die Weltherrschaft von Jahwe gegeben ist. - Ein weiteres Geheimnis wird man in den Worten nicht zu suchen haben. 